\title{
DTT: 20 Years and Counting ...
}

\author{
Satish K. Garg, MD
}

A s EDITOR-IN-CHIEF of Diabetes Technology \& Therapeutics (DTT), I am pleased that our journal continues to draw manuscripts from emerging technologies and new therapeutic options for diabetes. I am also happy to bring state-of-theart commentaries related to important manuscripts published in $D T T$. Specifically, DTT published the full report on the first hybrid closed-loop study (670G) in the March issue of $2017^{1}$, which highlighted the detailed data for adults and adolescents in the pivotal study that led to approval of the 670G by the FDA. In addition, we have been able to publish the first biosimilar rapidacting insulin analog (Humalog vs. SAR342434 insulin lispro) study in the September issue of $D T T .^{2}$ In addition, I was happy to write an editorial on my manuscript in the New England Journal of Medicine ${ }^{3}$ in our October issue of 2017, which highlighted expanding the treatment options for improving health outcomes for patients with type 1 diabetes. ${ }^{4}$ Specifically, I wanted to highlight that there is an urgent need for adjunctive therapy for patients with type 1 diabetes since the majority of patients are not achieving target A1cs and are getting overweight and/or obese. The editorial in the October issue is a hope that SGLT 1 and 2 inhibitors (Sotagliflozin) might become an option for patients with type 1 diabetes in an attempt to increase the number of patients achieving target A1cs without increasing hypoglycemia or weight. ${ }^{4}$ My goal is to encourage other lead authors and pharmaceutical companies to consider publishing original manuscripts in our journal.

DTT has high visibility throughout the world, with readers in over 174 countries. The journal averages nearly 16,000 full-text downloads per month, so if you publish in DTT you can be assured that your article will be widely read.

This special supplement includes advanced technologies and treatments for diabetes (ATTD) 2017 Yearbook, an invaluable resource for the most exciting and impactful manuscripts published from July 2016-June 2017. Most of the Yearbook chapters are written by key opinion leaders in the field of endocrinology and diabetes with invaluable expert commentaries. Publishing the Yearbook in DTT is vital because it means the articles are searchable in PubMed, Google, and other search engines.

I am grateful for the hard work by all the authors, especially Moshe Phillips and Tadej Battelino's ongoing leadership in organizing an important and outstanding annual ATTD conference being held in Vienna, February 14-17, 2018. I expect our continued friendship and partnership with ATTD will continue to grow.
The abstracts from the meeting are also included in this online supplement, giving readers and attendees a rich view into new and exciting work in technology and therapeutics.

DTT continues to be the official journal of the ATTD. Our partnership is very productive and effective in aligning the leading conference and the leading journal in the field of new technologies and treatments for diabetes.

I have a great editorial team starting off with Jay Skyler and Irl Hirsch as Senior Editors who continue to support the journal, and Irl writes his annual rant in the January/February issue of DTT each year. I sincerely thank Ananda Basu and Rita Basu for their important role as Associate Editors for the peer-review process. Recently, we added David Rodbard as a Deputy Editor to DTT. David has continued to be very helpful to the journal in the past ten years, especially helping me with the difficult manuscripts in the peer-review process. I look forward to working with David closely. As is traditional, we will also be changing some members of the DTT Editorial Board in 2018.

I am always looking forward to critics and active participation including your manuscript submissions and commentaries to the journal. I wish you all a great 2018 .

\section{References}

1. Garg SK, Weinzimer SA, Tamborlane WV, Buckingham BA, Bode BW, Bailey TS, Brazg RL, Ilany J, Slover RH, Anderson SM, Bergenstal RM, Grosman B, Roy A, Cordero TL, Shin J, Lee SW, and Kaufman FR: Glucose outcomes with the in-home use of a hybrid closed-loop insulin delivery system in adolescents and adults with type 1 diabetes. Diabetes Technol Ther 2017;19:155-163.

2. Garg SK, Wernicke-Panten K, Rojeski M, Pierre S, Kirchhein Y, Jedynasty K: Efficacy and safety of biosimilar SAR342434 insulin lispro in adults with type 1 diabetes also using insulin glargineSORELLA 1 study. Diabetes Technol Ther 2017;19:516-526.

3. Garg SK, Henry RR, Banks P, Buse JB, Davies MJ, Fulcher GR, Pozzilli P, Gesty-Palmer D, Lapuerta P, Simó R, Danne T, McGuire DK, Kushner JA, Peters A, Strumph P. Effects of sotagliflozin added to insulin in patients with type 1 diabetes. N Engl J Med 2017 Sep 13, doi:10.1056/NEJMoa1708337.

4. Garg SK: Expanding treatment options for improving health outcomes in type 1 diabetes. Diabetes Technol Ther 2017; 19:549-551.

Satish K. Garg, MD Editor-in-Chief

University of Colorado Denver and Barbara Davis Center for Diabetes, Aurora, Colorado. 